\begin{tabular}{|l|l|l|l|l|}
\hline $\mathrm{M}$ & $\mathrm{R}$ & $\mathrm{S}$ & Internet Journal of & Nitride Semiconductor Research \\
\hline
\end{tabular}

Volume 2, Article 5

\title{
Characteristics Of Room Temperature-CW Operated InGaN Multi-Quantum-Well-Structure Laser Diodes
}

\author{
Shuji Nakamura \\ Nichia Chemical Industries \\ This invited article was received on March 5, 1997 and accepted on March 11, 1997.
}

\begin{abstract}
The continuous-wave (CW) operation of InGaN multi-quantum-well-structure laser diodes (LDs) was demonstrated at room temperature (RT) with a lifetime of 35 hours. The threshold current and the voltage of the LDs were $80 \mathrm{~mA}$ and $5.5 \mathrm{~V}$, respectively. The threshold current density was $3.6 \mathrm{kA} / \mathrm{cm}^{2}$. When the temperature of the LDs was varied, large mode hopping of the emission wavelength was observed. The carrier lifetime and the threshold carrier density were estimated to be $2-10 \mathrm{~ns}$ and $1-2 \times 10^{20} / \mathrm{cm}^{3}$, respectively. From the measurements of gain spectra and an external differential quantum efficiency dependence on the cavity length, the differential gain coefficient, the transparent carrier density, threshold gain and internal loss were estimated to be $5.8 \times 10^{-17} \mathrm{~cm}^{2}, 9.3 \times 10^{19} \mathrm{~cm}^{-3}, 5200 \mathrm{~cm}^{-1}$ and $43 \mathrm{~cm}^{-1}$, respectively.
\end{abstract}

\section{INTRODUCTION}

Short-wavelength-emitting devices, such as blue laser diodes (LDs), are currently required for a number of applications, including full-color electroluminescent displays, laser printers, read-write laser sources for high-density information storage on magnetic and optical media, and sources for undersea optical communications. Major developments in wide-gap III-V nitride semiconductors have recently led to the commercial production of high-brightness blue/green light-emitting diodes (LEDs) [1] and to the demonstration of room-temperature (RT) violet laser light emission in In GaN/GaN/AIGaN-based heterostructures under pulsed currents [2] [3] [4] [5] [6] [7] [8] and continuous-wave (CW) operation [9] [10]. These developments are a result of the realization of high-quality crystals of AIGaN and InGaN, and p-type conduction in AIGaN [11] [12] [13] [14]. The recombination of localized excitons has been proposed as an emission mechanism for these InGaN quantum-well-structure LEDs[15] [16] [17]. The radiative recombination of the spontaneous and stimulated emission of the InGaN MQW LEDs and LDs was attributed to excitons (or carriers) localized at deep traps $(250 \mathrm{meV})$ which originated from the In-rich region in the InGaN wells acting as quantum dots [15] [16] [17]. The fundamental properties of semiconductor lasers are specified by the optical gain. However, experimental data regarding the optical gain of RT CW-operated III-V nitride-based LDs have not been reported. Recently, RT CW operation of the InGaN MQW LDs with a lifetime of 35 hours has been achieved [18]. Using these RT CW-operated LDs, it is interesting to measure the characteristics of the LDs in detail especially those of the emission mechanism. In this paper, we report the optical gain and the emission characteristics of InGaN MQW LDs. For the measurement of the optical gain of the LDs, the Hakki-Paoli technique was used [19].

\section{EXPERIMENT}

III-V nitride films were grown by the two-flow metalorganic chemical vapor deposition (MOCVD) method. Details of two-flow MOCVD have been described elsewhere [20]. The growth was conducted at atmospheric pressure, and (0001) C-face sapphire was used as the substrate. The InGaN MQW LD device consisted of a 300-Aि-thick GaN buffer layer grown at a low temperature of $550^{\circ} \mathrm{C}$, a 3- $\mu \mathrm{m}$-thick layer of n-type $\mathrm{GaN}: \mathrm{Si}$, a $0.1-\mu \mathrm{m}$-thick layer of n-type In ${ }_{0.05} \mathrm{Ga}_{0.95} \mathrm{~N}: \mathrm{Si}$, a $0.5-\mu \mathrm{m}$-thick layer of $\mathrm{n}$-type $\mathrm{Al}_{0.08} \mathrm{Ga}_{0.92} \mathrm{~N}: \mathrm{Si}$, a $0.1-\mu \mathrm{m}$-thick layer of $\mathrm{n}$-type $\mathrm{GaN}: \mathrm{Si}$, an $\mathrm{In}_{0.15} \mathrm{Ga}$ $0.85 \mathrm{~N} / \mathrm{In}_{0.02} \mathrm{Ga}_{0.98} \mathrm{~N}$ MQW structure consisting of four 35 - $\AA$-thick $S$ i-doped $\ln _{0.15} \mathrm{Ga}_{0.85} \mathrm{~N}$ well layers forming a gain medium senarated hv 70-Å-thick Si-dnned Inn nnGan noN harrier lavers. a 20n- $\AA$-thick laver nf $n$-tvne Aln nGa 
$0.8 \mathrm{~N}: \mathrm{Mg}$, a $0.1-\mu \mathrm{m}$-thick layer of $\mathrm{p}$-type $\mathrm{GaN}: \mathrm{Mg}$, a $0.5-\mu \mathrm{m}$-thick layer of $\mathrm{p}$-type $\mathrm{Al}_{0.08} \mathrm{Ga}_{0.92} \mathrm{~N}: \mathrm{Mg}$, and a $0.5-\mu \mathrm{m}$-thick layer of $p$-type GaN:Mg. The 0.1- $\mu \mathrm{m}$-thick $n$-type and $p$-type GaN layers were light-guiding layers. The $0.5 \mu \mathrm{m}$-thick n-type and p-type $\mathrm{Al}_{0.08} \mathrm{Ga}_{0.92} \mathrm{~N}$ layers acted as cladding layers for confinement of the carriers and the light emitted from the active region of the InGaN MQW structure. The structure of the ridge-geometry InGaNMQW LD was almost the same as that described previously [6].

First, the surface of the p-type GaN layer was partially etched until the n-type GaN layer and the p-type $A b .08 \mathrm{Ga}_{0.92} \mathrm{~N}$ cladding layer were exposed, in order to form a ridge-geometry LD [6]. A mirror facet was also formed by dry etching, as reported previously [2]. The area of the ridge-geometry LD was $4 \mu \mathrm{m} \times 550 \mu \mathrm{m}$. High-reflection facet coatings (50 $\%$ ) consisting of 2 pairs of quarter-wave $\mathrm{TiO}_{2} / \mathrm{SiO}_{2}$ dielectric multilayers were used to reduce the threshold current. $\mathrm{A}$ $\mathrm{Ni} / \mathrm{Au}$ contact was evaporated onto the $\mathrm{p}$-type GaN layer, and a Ti/Al contact was evaporated onto the n-type GaN layer. The electrical characteristics of the LDs fabricated in this way were measured under a direct current (DC). The structure of the InGaN MQW LDs is shown in Figure 1.

\section{RESULTS AND DISCUSSION}

In previously reported structures, the InGaN well and barrier layers were undoped. In the present structures, Si was doped into these layers to reduce the threshold current density and operating voltage. Recently, the recombination of excitons localized at certain potential minima in an InGaN quantum well was proposed as the emission mechanism for InGaN SQW LEDs and MQW LEDs [15] [16] [17]. It was suggested that these localized excitons, or zero-dimensional quantum dots, were related to the emission mechanism for InGaN MQW LDs [15] [16] [17]. The exact effect of Si doping is not clear at present. However, there is a possibility that Si doping enhances the formation of a localized state and, as a result, a quantum dot-like state in the InGaN well layer. Also, the temperature of thermal annealing for Mg-doped GaN and AIGaN layers to activate Mg acceptors was changed from $700^{\circ} \mathrm{C}$ to $600^{\circ}$ $\mathrm{C}$ after evaporation of $\mathrm{Ni} / \mathrm{Au}$ metal in order to reduce the contact resistance of the $\mathrm{p}$-electrode. The low-temperature thermal annealing probably prevents dissociation of GaN and InGaN layers.

Figure 2 shows typical voltage-current (V-I) characteristics and the light output power per coated facet of the LD as a function of the forward DC current (L-I) at RT. No stimulated emission was observed up to a threshold current of 80 $\mathrm{mA}$, which corresponded to a threshold current density of $3.6 \mathrm{kA} / \mathrm{cm}^{2}$, as shown in Figure 2. The operating voltage at the threshold current was $5.5 \mathrm{~V}$. We were able to reduce the operating voltage significantly in comparison with values obtained previously (about 20-30 V) by adjusting the growth, Ohmic contact and doping profile conditions [2] $[3][4][5][6][7]$.

Figure 3 shows the results of a lifetime test of CW-operated LDs carried out at RT, in which the operating current is shown as a function of time under a constant output power of $1.5 \mathrm{~mW}$ per facet controlled using an autopower controller (APC). The operating current gradually increases due to the increase in the threshold current from the initial stage and sharply increases after 35 hours. This short lifetime is probably due to the large heat generation resulting from the high operating currents and voltages. Breakdown of the LDs occurred after a period of more than 35 hours due to the formation of a short circuit in the LDs.

Next, the emission spectra of the LDs were measured under RT CW operation at an output power of $1 \mathrm{~mW}$. An optical spectrum analyzer (ADVANTEST Q8347) which utilized the Fourier-transform spectroscopy method by means of a Michelson interferometer was used to measure the spectra of the LDs with a resolution of $0.001 \mathrm{~nm}$. At $\mathrm{J}$ $=1.0 \mathrm{~J}_{\text {th }}$, where $\mathrm{J}$ is the current density and $\mathrm{J}_{\text {th }}$ is the threshold current density, longitudinal modes with many sharp peaks with a peak separation of $0.042 \mathrm{~nm}(\Delta \mathrm{E}=0.3 \mathrm{meV}$, where $\Delta \mathrm{E}$ was the mode separation energy) were observed, as shown in Figure 4(a). If these peaks arise from the longitudinal modes of the LD, then the mode separation $\Delta \lambda$ is given by

$$
\Delta \lambda=\lambda_{0}^{2} /\left(2 \operatorname{Ln}_{\text {eff }}\right)
$$

where $n_{\text {eff }}$ is the effective refractive index and $\lambda_{0}$ is the emission wavelength $(405.83 \mathrm{~nm})$. $L$ is $0.055 \mathrm{~cm}$. Thus, $n_{\text {eff }}$ is calculated as 3.6, which is relatively large due to the wavelength and temperature dependence of the refractive indices of $\mathrm{GaN}$ and InGaN. Also, other periodic subband emissions are observed with a peak separation of 0.25-0.29 $\mathrm{nm}(\Delta \mathrm{E}=1.8-2.1 \mathrm{meV})$. The origin of these subband emissions has not yet been clarified. At $\mathrm{J}=1.2 \mathrm{~J}_{\mathrm{th}}$, the main peak at $405.83 \mathrm{~nm}$ becomes dominant, as shown in Figure 4(b).

The temperature dependence of the emission spectra was measured between $20^{\circ} \mathrm{C}$ and $60{ }^{\circ} \mathrm{C}$ under $\mathrm{CW}$ operation with a constant output power of $1 \mathrm{~mW}$, as shown in Figure 5. Large mode hopping of the peak emission 
wavelength with an energy step of 1-7 meV is observed, which results from the temperature dependence of the gain profile. The change in the actual emission spectra with temperature between $47^{\circ} \mathrm{C}$ and $48^{\circ} \mathrm{C}$ is shown in Figure 6. When the temperature is increased from $47^{\circ} \mathrm{C}$ to $48^{\circ} \mathrm{C}$, the peak wavelength varies from $407.428 \mathrm{~nm}$ to $408.523 \mathrm{~nm}$ (with an energy difference of $7 \mathrm{meV}$ ) due to the change in the gain profile.

Next, the delay time of the laser emission of the LDs as a function of the operating current was measured under pulsed current modulation using the method described in ref. [7] in order to estimate the carrier lifetime $\left(\tau_{\mathrm{s}}\right)$. The delay time $t_{d}$ is given by

$$
t_{d}=\tau_{s} \ln \left(I /\left(I-I_{t h}\right)\right)
$$

where $\tau_{\mathrm{s}}$ is the minority carrier lifetime, $I$ is the pumping current, and $\mathrm{l}_{\mathrm{t}}$ is the threshold current. Figure 7 shows the delay time $t_{d}$ of the laser emission as a function of $\ln \left(I /\left(I-I_{t h}\right)\right)$. From this figure, $\tau_{s}$ was estimated to be $10 \mathrm{~ns}$, which was relatively large in comparison with the previous value of $3.2 \mathrm{~ns}$ [7]. The threshold carrier density $\left(n_{\mathrm{th}}\right)$ was

estimated to be $2 \times 10^{20} / \mathrm{cm}^{3}$ for a threshold current density of $3.6 \mathrm{kA} / \mathrm{cm}^{2}$, a carrier lifetime of $10 \mathrm{~ns}$, and an active layer thickness of $140 \AA$ [7]. The thickness of the active layer was determined as $140 \AA$ assuming that the injected carriers were confined in the InGaN well layers in the active layer. In comparison with these values for conventional lasers, $n_{\text {th }}$ for our structure is relatively large (two orders of magnitude higher), probably due to the large density of states of carriers resulting from their large effective masses [7].

Figure 8 shows the reciprocal of the external differential quantum efficiency of the LDs with an uncoated facet as a function of the cavity length. The external differential quantum efficiency decreases with increasing cavity length. The external differential quantum efficiency is given by

$$
1 / \eta_{d}=a_{i} L / \ln (1 / R) / \eta_{i}+1 / \eta_{i}
$$

where $\eta_{d}$ is the external differential quantum efficiency, $\alpha_{i}$ is the internal loss, $L$ is the cavity length, $R(22 \%)$ is the reflection coefficient of the uncoated facet, and $\eta_{i}$ is the internal quantum efficiency. Therefore, $1 / \eta_{d}$ is proportional to $L$, as shown in Figure 8. From the figure, $\alpha_{i}$ and $\eta_{i}$ are calculated as $43 \mathrm{~cm}^{-1}$ and $76 \%$, respectively.

The emission spectra of the LD with a short cavity length of $150 \mu \mathrm{m}$ were measured under RT CW operation. Figure 9 shows the spontaneous and stimulated emission spectra of the InGaN MQW LD with a various operating current. Below $53 \mathrm{~mA}$, many longitudinal modes appear with a mode separation of $0.125 \mathrm{~nm}$. If these peaks arise from the longitudinal modes of the LD, then the mode separation $\Delta \lambda$ is given by $\Delta \lambda=\lambda_{0}{ }^{2} /\left(2 L n_{\text {eff }}\right)$, where $n_{\text {eff }}$ is the effective refractive index and $\lambda_{0}$ is the emission wavelength $(400.2 \mathrm{~nm}) . L$ is $0.015 \mathrm{~cm}$. Thus, $n_{\text {eff }}$ was calculated as 4.3 , which is relatively large due to the wavelength and temperature dependence of the refractive indices of GaN and InGaN. The full-width at half maximum (FWHM) of the spontaneous emission at $50 \mathrm{~mA}$ was about $30 \mathrm{meV}$ which was relatively large considering the random mixing of InGaN ternary compounds (alloy broadening is $10 \mathrm{meV}$ ) probably due to an In composition fluctuation of InGaN MQW resulting from an InGaN phase separation [15] [16] [17]. The lasing wavelength of the LD is $400.2 \mathrm{~nm}(3.098 \mathrm{eV})$ as shown in Figure $9 \mathrm{~d}$.

Figure 10 shows the net modal gain spectra of each emission spectrum shown in Figure 9. The reflectivity $(R)$ of the mirror facet was $50 \%$. The cavity length $(L)$ was $0.015 \mathrm{~cm}$. Using these values, the mirror loss $L^{-1} \ln (1 / R)$ was calculated to be $46 \mathrm{~cm}^{-1}$. The devices lased in the transverse-electric (TE) mode at a threshold current of $53 \mathrm{~mA}$, where the peak net modal gain was almost equal to $\mathrm{L}^{-1} \ln (1 / R)=46 \mathrm{~cm}^{-1}$. As the current was increased, the position of the gain maximum shifted to shorter wavelengths.

Figure 11 shows the current dependence of the net modal gain at a specified wavelength of $400.2 \mathrm{~nm}$. This specified wavelength was selected to be a peak of the stimulated emission, as shown in Figure 10. From the current dependence of the net modal gain of $400.2 \mathrm{~nm}$ at currents between 10 and $50 \mathrm{~mA}$, the gain maximum of the material is expressed $\left(g_{\max }\right)$ as a function of the current density $(\mathrm{J})$,

$$
\text { net modal gain }=\Gamma g_{\max }-\alpha_{i}=0.03 \mathrm{~J}-180 \mathrm{~cm}^{-1} \text {, }
$$




$$
g_{\max }=1.2 \mathrm{~J}-5400 \mathrm{~cm}^{-1}
$$

assuming that $\alpha_{i}$ is $43 \mathrm{~cm}^{-1}$ and that an optical confinement factor $(\Gamma)$ of the LDs is 0.025 which was estimated from a measurement of near-field radiation patterns [21]. From equation 5

$$
g_{\mathrm{th}}=1.2 \mathrm{~J}_{\mathrm{th}}-5400 \mathrm{~cm}^{-1} \text {, }
$$

where $J_{\text {th }}$ is a threshold current density of $8.8 \mathrm{kA} / \mathrm{cm}^{2}$. From equation $6, \mathrm{~g}_{\text {th }}$ was estimated to be $5200 \mathrm{~cm}^{-1}$ at a threshold current density of $8.8 \mathrm{kA} / \mathrm{cm}^{2}$.

The delay time of the laser emission as a function of the operating current was measured under pulsed current modulation of the LDs in order to estimate the carrier lifetime $\left(\tau_{\mathrm{s}}\right)$. From this measurement, $\tau_{\mathrm{s}}$ was estimated to be $3.5 \mathrm{~ns}$. The threshold carrier density $\left(n_{\mathrm{th}}\right)$ was estimated to be $1.9 \times 10^{20} / \mathrm{cm}^{3}$ using a threshold current density of

$8.8 \mathrm{kA} / \mathrm{cm}^{2}$, a carrier lifetime of $3.5 \mathrm{~ns}$, and an active layer thickness of $105 \AA$. Using these values of carrier lifetime and active layer thickness, equation 5 can be expressed as a function of the carrier density ( $\mathrm{n}$ ), as shown in equation 7

$$
g_{\max }=5.8 \times 10^{-17}\left(\mathrm{n}-9.3 \times 10^{19}\right) \mathrm{cm}^{-1} .
$$

From this equation, the differential gain coefficient and the transparent carrier density are estimated to be $5.8 \times 10^{-17}$ $\mathrm{cm}^{2}$ and $9.3 \times 10^{19} \mathrm{~cm}^{-3}$, respectively. Suzuki and Uenoyama reported that the transparent carrier density is as high as $1-2 \times 10^{19} \mathrm{~cm}^{-3}$ for a $30-\AA$-thick $\mathrm{GaN} / \mathrm{Al}_{0.2} \mathrm{Ga}_{0.8} \mathrm{~N}$ quantum well structure [22]. Chow et al. [23] calculated the transparent carrier density as $1 \times 10^{19} \mathrm{~cm}^{-3}$ for 60 - $\AA$-thick $\mathrm{GaN} / \mathrm{Al}_{0.14} \mathrm{Ga}_{0.86} \mathrm{~N}$ strained quantum well LDs. The transparent carrier density of the InGaN MQW LDs is relatively large in comparison with their calculated values. The value of differential gain is also relatively small in comparison with those of conventional AIGaAs or AIGalnP MQW LDs.

\section{SUMMARY}

In summary, the RT CW operation of InGaN MQW LDs was demonstrated with a lifetime of 35 hours. The laser emission was fundamental single mode emission with a peak wavelength of $400-405 \mathrm{~nm}$. The carrier lifetime and the threshold carrier density were estimated to be $2-10$ ns and $1-2 \times 10^{20} / \mathrm{cm}^{3}$, respectively. The differential gain coefficient, the transparent carrier density, threshold gain and internal loss were estimated to be $5.8 \times 10^{-17} \mathrm{~cm}^{2}$, $9.3 \times 10^{19} \mathrm{~cm}^{-3}, 5200 \mathrm{~cm}^{-1}$ and $43 \mathrm{~cm}^{-1}$, respectively. The differential gain is relatively small considering that the active layer of the LD is a MQW or quantum dot-like structure probably due to large inhomogeneities in the $\ln G a N$ active layer.

\section{References}

[1] S. Nakamura, M. Senoh, N. Iwasa, S. Nagahama, T. Yamada, T. Mukai, Jpn. J. Appl. Phys. 34, L1332-L1335 (1995).

[2] S Nakamura, M Senoh, S Nagahama, N Iwasa, T Yamada, T Matsushita, H Kiyoku, Y Sugimoto, Jpn. J. Appl. Phys. 35, L74-L76 (1996).

[3] S. Nakamura, M. Senoh, S. Nagahama, N. Iwasa, T. Yamada, T. Matsushita, H. Kiyoku, Y. Sugimoto, Jpn. J. Appl. Phys. 35, L217-L220 (1996).

[4] Shuji Nakamura, Masayuki Senoh, Shin-ichi Nagahama, Naruhito Iwasa, Takao Yamada, ToshioMatsushita, Hiroyuki Kiyoku, Yasunobu Sugimoto, Appl. Phys. Lett. 68, 2105-2107 (1996).

[5] Shuji Nakamura, Masayuki Senoh, Shin-ichi Nagahama, Naruhito Iwasa, Takao Yamada, ToshioMatsushita, 
Hiroyuki Kiyoku, Yasunobu Sugimoto, Appl. Phys. Lett. 68, 3269-3271 (1996).

[6] S. Nakamura, M. Senoh, S. Nagahama, N. Iwasa, T. Yamada, T. Matsushita, Y. Sugimoto, H. Kiyoku, Appl. Phys. Lett. 69, 1477-1479 (1996).

[7] S. Nakamura, M. Senoh, S. Nagahama, N. Iwasa, T. Yamada, T. Matsushita, Y. Sugimoto, H. Kiyoku, Appl. Phys. Lett. 69, 1568-1570 (1996).

[8] K. Itaya, M. Onomura, J. Nishio, L. Sugiura, S. Saito, M. Suzuki, J. Rennie, S. Nunoue, M. Yamamato, H. Fujimoto, Y. Kokobun, Y. Ohba, G. Hatakoshi, M. Ishikawa, Jpn. J. Appl. Phys. 35, I1315-I1317 (1996).

[9] S. Nakamura, M. Senoh, S. Nagahama, N. Iwasa, T. Yamada, T. Matsushita, Y. Sugimoto, H. Kiyoku, Appl. Phys. Lett. 69, 3034-3036 (1996).

[10] S. Nakamura, M. Senoh, S. Nagahama, N. Iwasa, T. Yamada, T. Matsushita, Y. Sugimoto, H. Kiyoku, Appl. Phys. Lett. 69, 4056-4058 (1996).

[11] H. Morkoc, S. Strite, G. B. Gao, M. E. Lin, B. Sverdlov, M. Burns , J. Appl. Phys. 76, 1363-1398 (1994).

[12] H. Amano, M. Kito, K. Hiramatsu, I. Akasaki, Jpn. J. Appl. Phys. 28, L2112 (1989).

[13] S. Nakamura, T. Mukai, Jpn. J. Appl. Phys. 31, L1457-L1459 (1992).

[14] M. Asif Khan, J. N. Kuznia, D. T. Olson, M. Blasingame, A. R. Bhattarai , Appl. Phys. Lett. 63, 2455-2456 (1993).

[15] S. Chichibu, T. Azuhata, T. Sota, S. Nakamura, Appl. Phys. Lett. 69, 4188-4190 (1996).

[16] Y. Narukawa, Y. Kawakami, Sz. Fujita, Sg. Fujita, S. Nakamura, Phys. Rev. B 55, 1938R-1941R (1997).

[17] Y. Narukawa, Y. Kawakami, M. Funato, S. Fujita, S. Fujita, S. Nakamura, Appl. Phys. Lett. 70, 981-983 (1997).

[18]S. Nakamura, presented at Materials Research Society Fall Meeting, N1.1, Dec. 2-6, Boston, (1996)

[19] B. W. Hakki, T. L. Paoli, J. Appl. Phys. 44, 4113-4119 (1973).

[20] S. Nakamura, Jpn. J. Appl. Phys. 30, 1620 (1991).

[21] S. Nakamura, M. Senoh, S. Nagahama, N. Iwasa, T. Yamada, T. Matsushita, Y. Sugimoto, H. Kiyoku, unpublished (1997).

[22] M Suzuki, T Uenoyama, Jpn. J. Appl. Phys. 35, 1420 (1996).

[23] W. W. Chow, A. F. Wright, J. S. Nelson, Appl. Phys. Lett. 68, 296-298 (1996). 


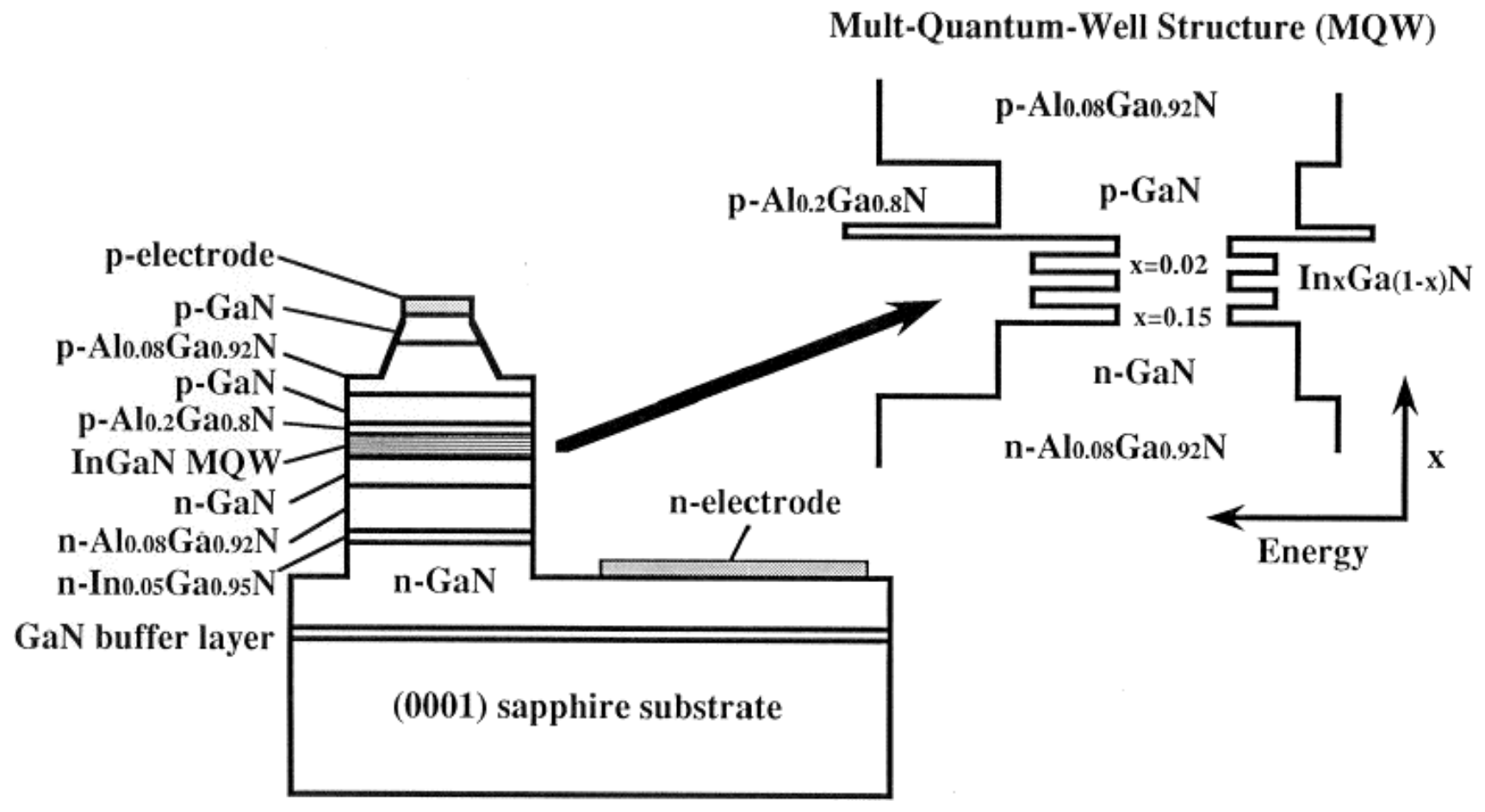

Figure 1. The structure of the InGaN MQW LDs.

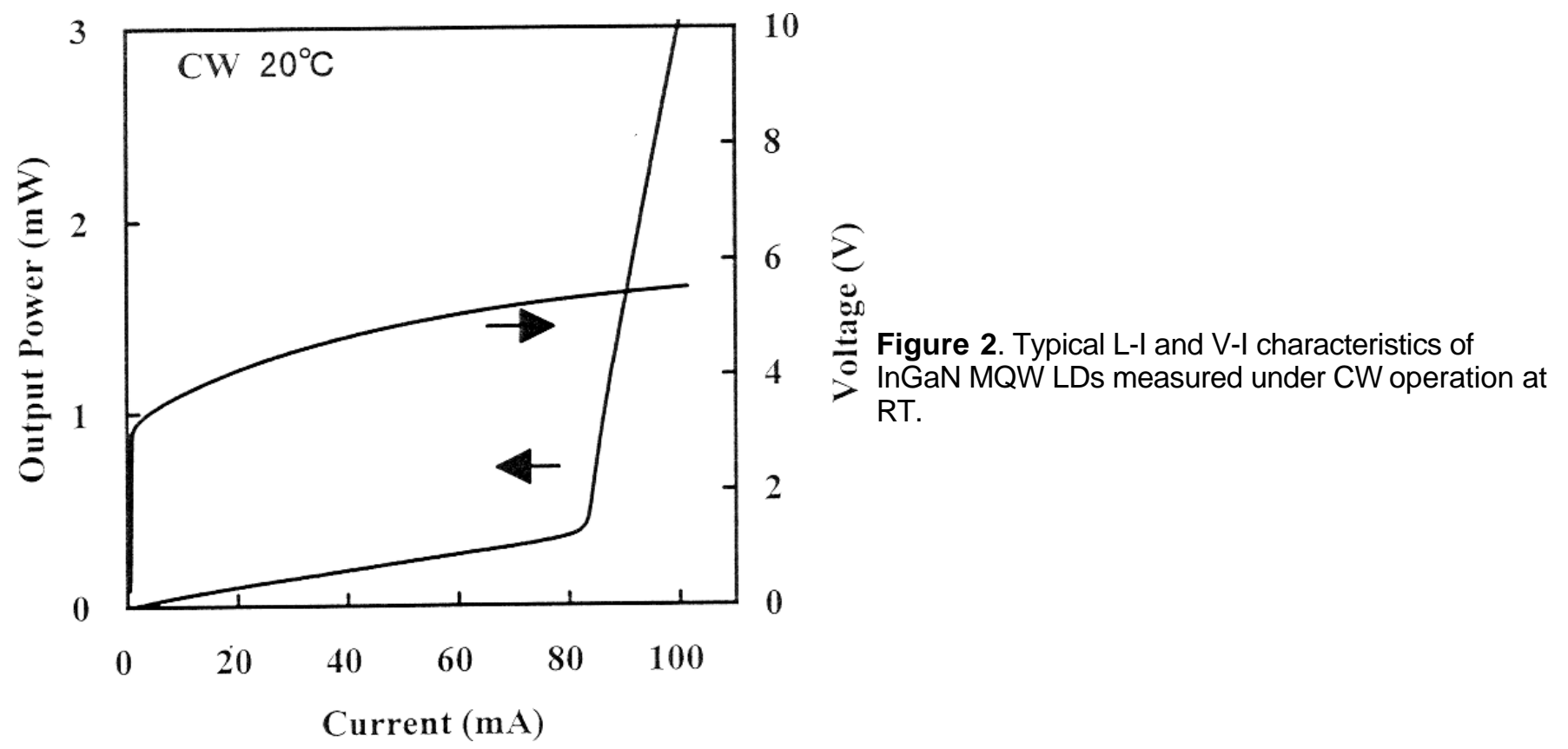



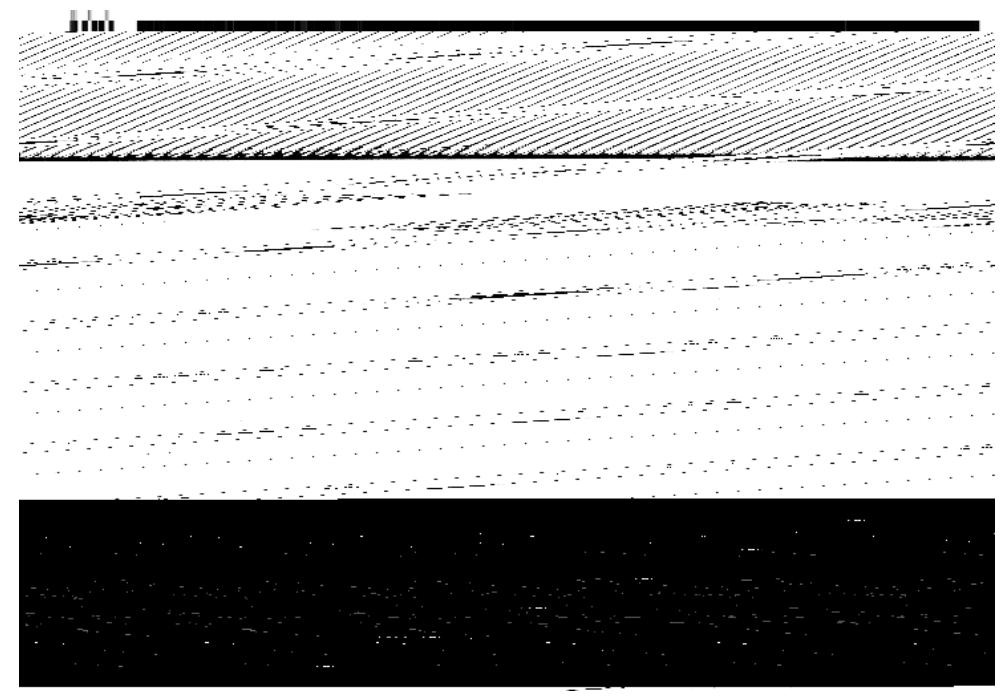

Figure 3. Operating current as a function of time under a constant output power of $1.5 \mathrm{~mW}$ per facet controlled using an autopower controller. The LD was operated under DC at RT.

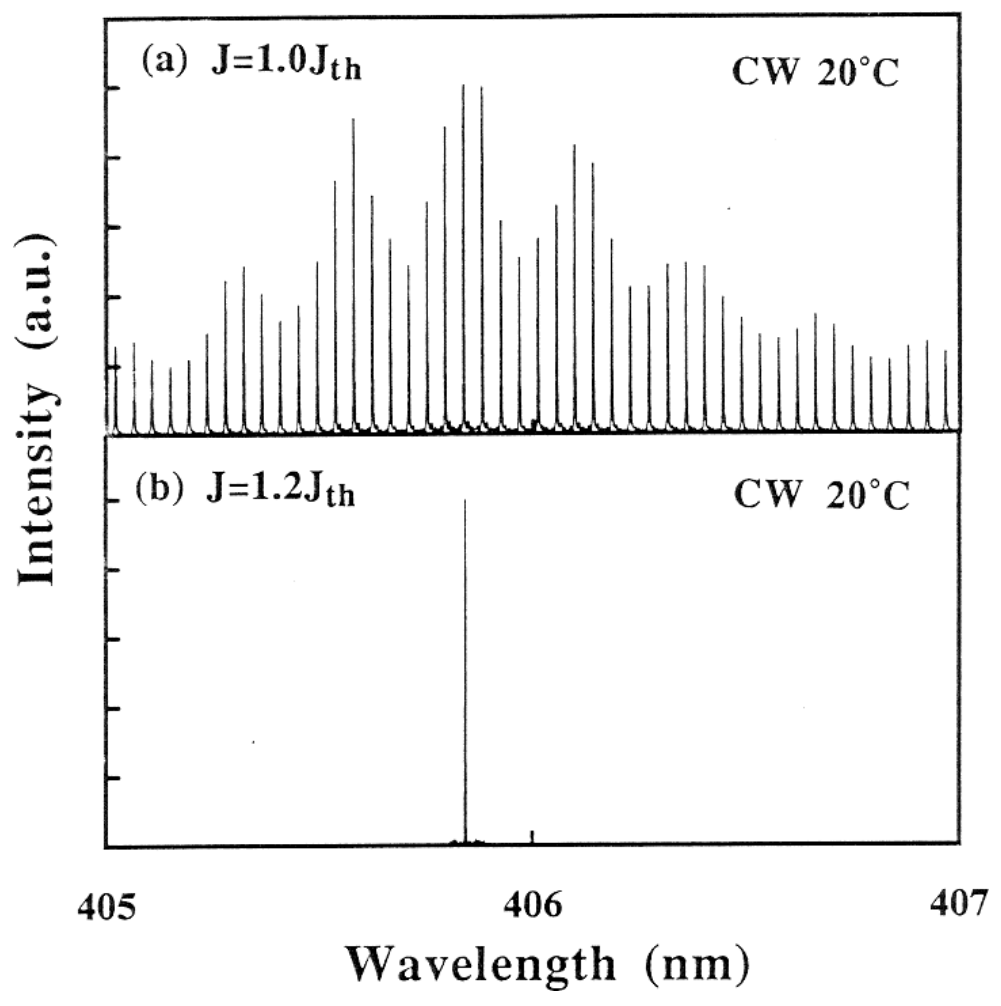

Figure 4. Laser emission spectra measured under RT CW operation with current densities of (a) $\mathrm{J}=$ $1.0 \mathrm{~J}_{\text {th }}$ (b) $\mathrm{J}=1.2 \mathrm{~J}_{\mathrm{th}}$. 

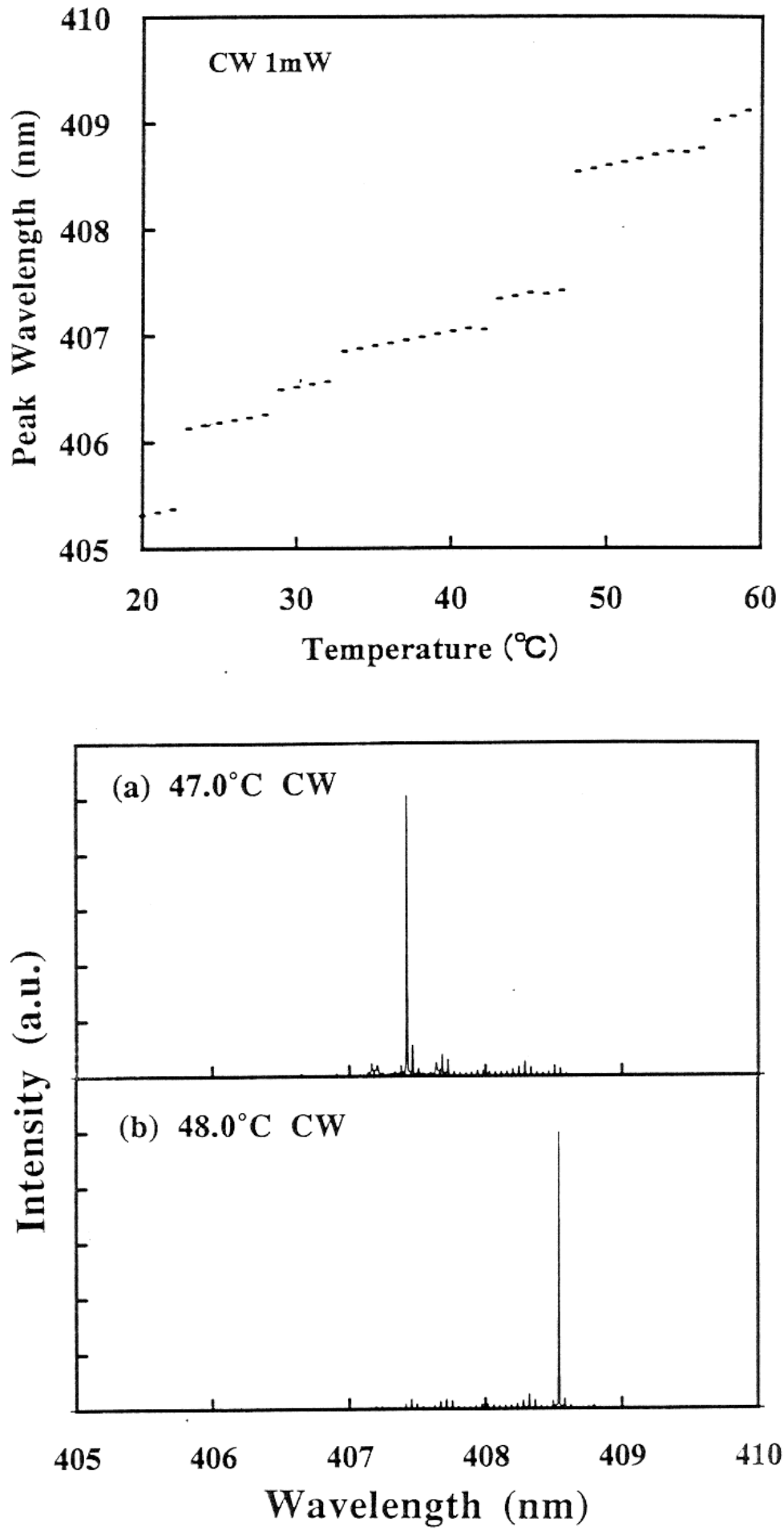

Figure 5. Temperature dependence of the peak emission wavelengths of InGaN MQW LDs under CW operation with a constant output power of 1 $\mathrm{mW}$.

Figure 6. Optical spectra of InGaN MQW LDs measured under $\mathrm{CW}$ operation at temperatures of (a) $47^{\circ} \mathrm{C}$ and (b) $48^{\circ} \mathrm{C}$. The intensity scales for these two spectra are in arbitrary units, and each one is different. 

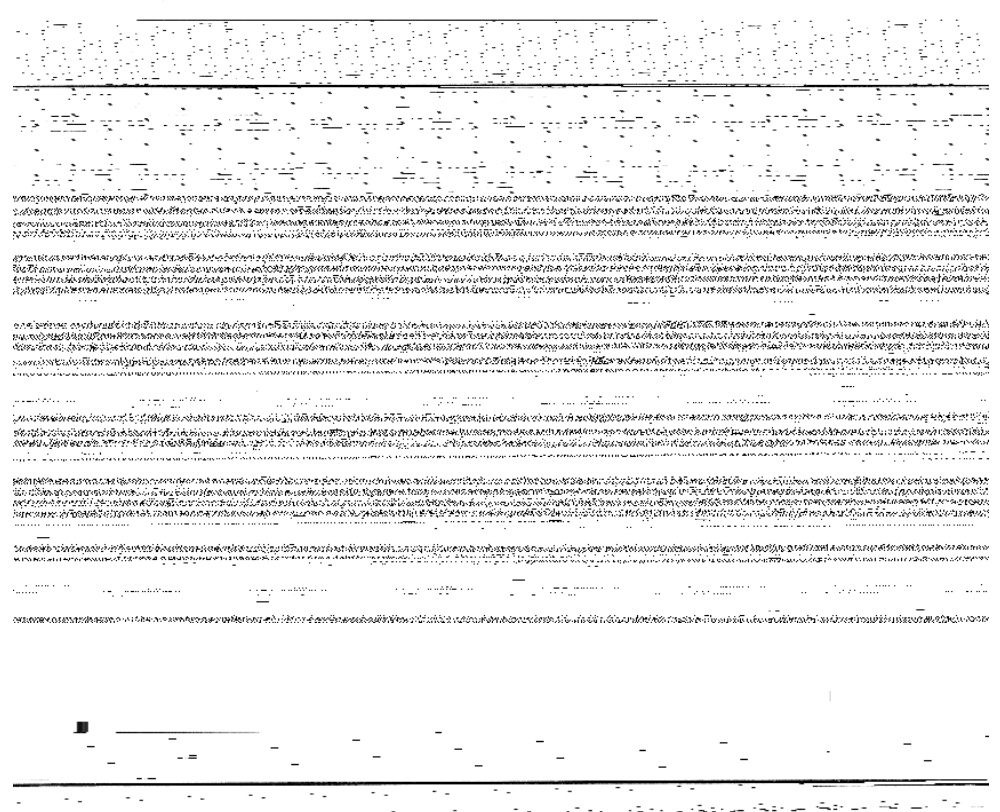

(1)

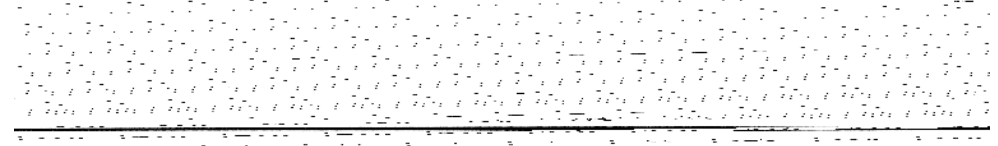

$=$
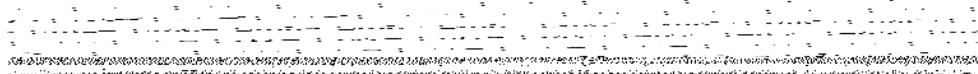

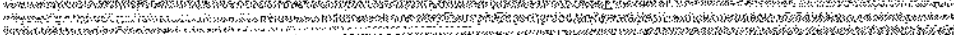

A 1.

Pis

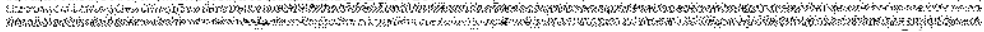

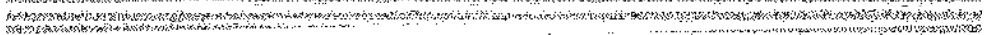

wind

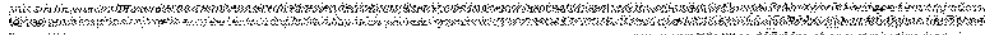

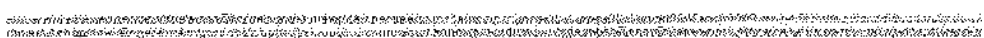

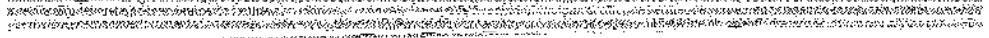

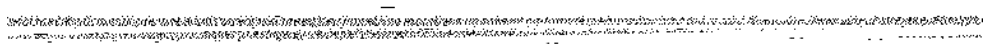

Figure 7. The delay time $t_{d}$ of the laser emission as a function of $\ln \left(\mid /\left(I-I_{t h}\right)\right)$. I is the pumping current and $\mathrm{I}_{\mathrm{th}}$ is the threshold current.
Figure 8. The reciprocal of the external differential quantum efficiency of the LDs with an uncoated facet as a function of the various cavity length. 


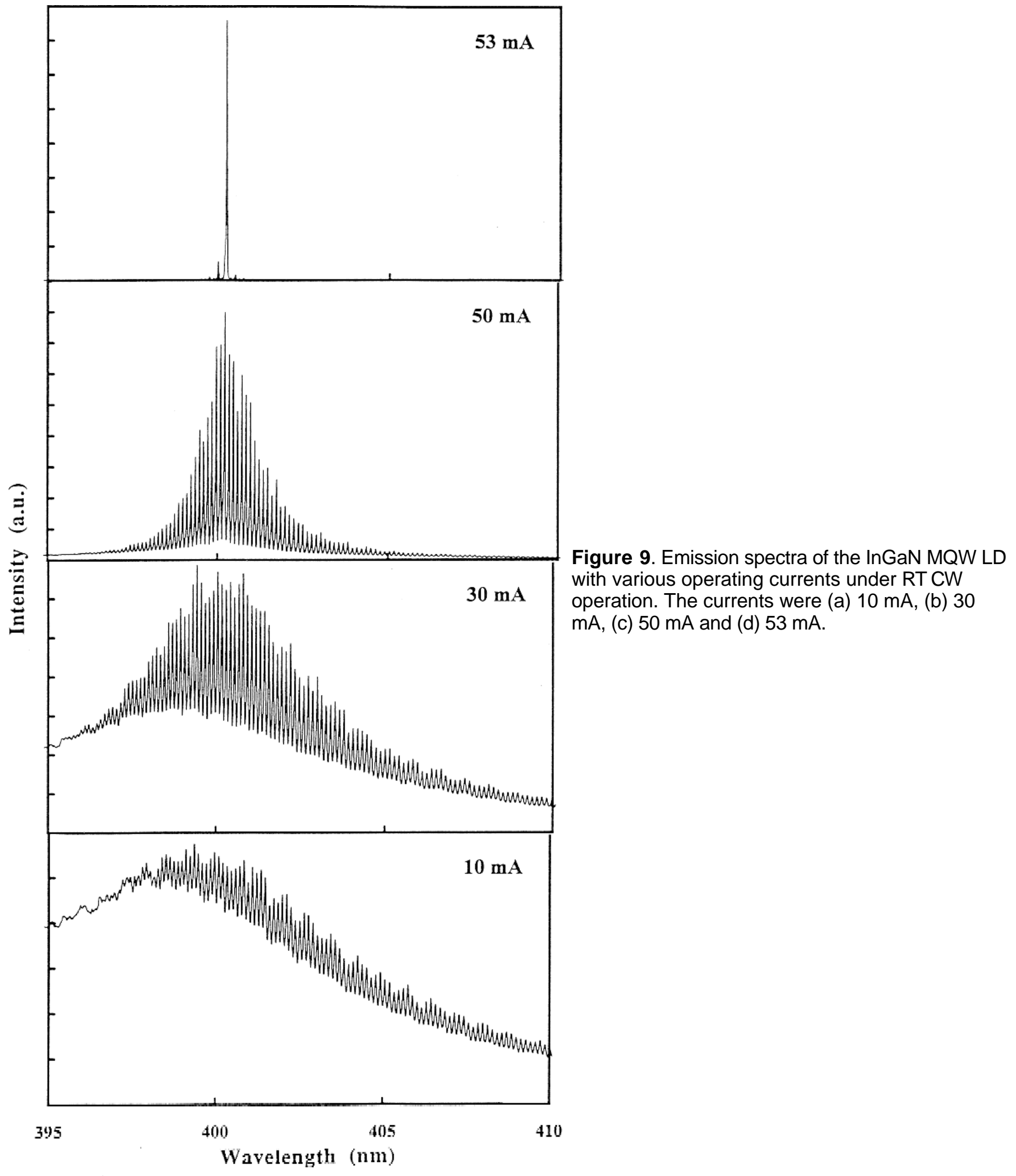




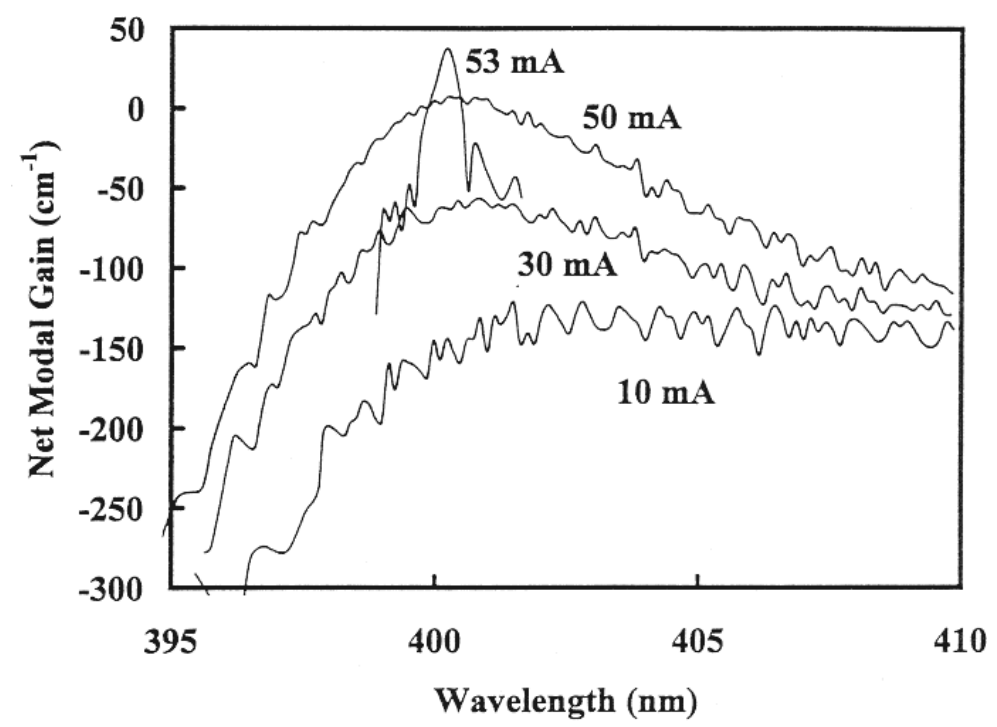

Figure 10. The net modal gain spectra of the InGaN MQW LD from $10 \mathrm{~mA}$ to $50 \mathrm{~mA}$ under RT CW operation.

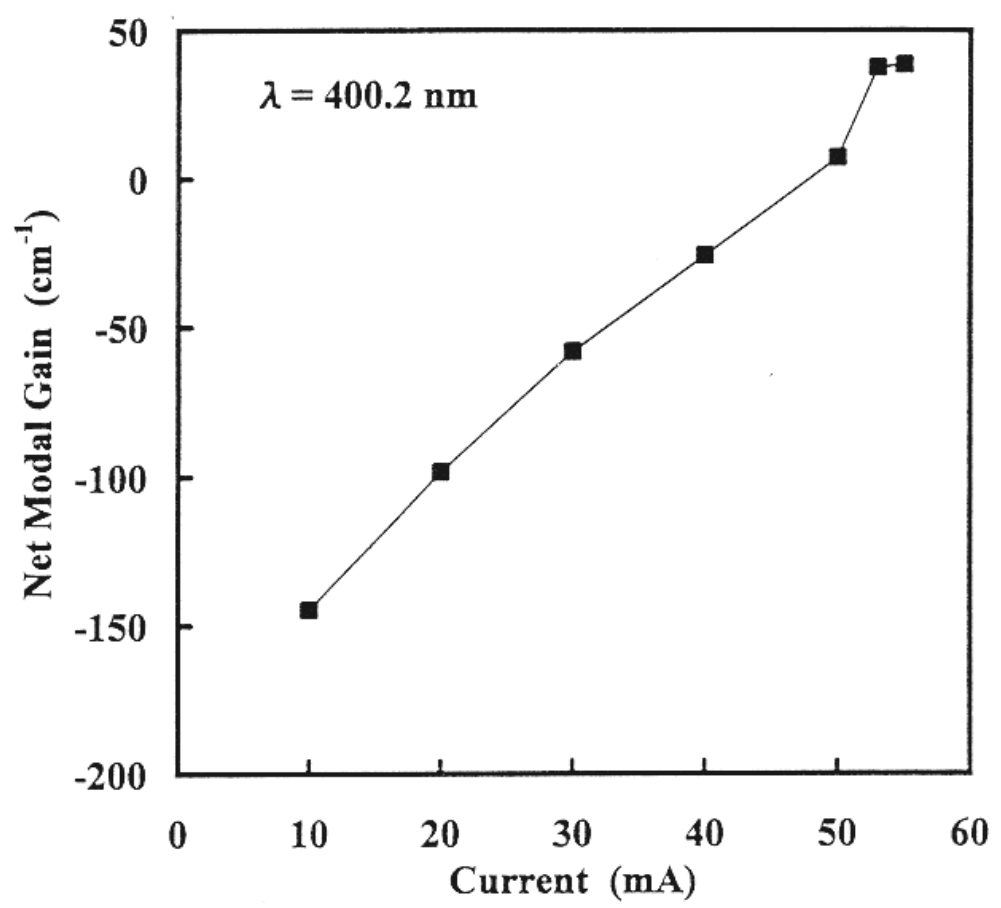

Figure 11. Injection current dependence of the net modal gain at a wavelengths of $400.2 \mathrm{~nm}$.

(C) 1997 The Materials Research Society

\begin{tabular}{|c|c|c|c|}
\hline & $\mathrm{R}$ & $S$ Internet Journal of & Nitride Semiconductor Research \\
\hline
\end{tabular}

